University of Nebraska - Lincoln

DigitalCommons@University of Nebraska - Lincoln

US Department of Energy Publications

U.S. Department of Energy

2005

\title{
Fluorescence spectroscopy of $\mathrm{U}(\mathrm{VI})$-silicates and $\mathrm{U}(\mathrm{VI})$ - contaminated Hanford sediment
}

\author{
Zheming Wang \\ Pacific Northwest National Laboratory, Zheming.wang@pnl.gov \\ John M. Zachara \\ Pacific Northwest National Laboratory, john.zachara@pnl.gov \\ Paul Gassman \\ Pacific Northwest National Laboratory, paul.gassman@pnl.gov \\ Chongxuan Liu \\ Pacific Northwest National Laboratory, chongxuan.liu@pnl.gov \\ Odeta Qafoku \\ Pacific Northwest National Laboratory \\ See next page for additional authors
}

Follow this and additional works at: https://digitalcommons.unl.edu/usdoepub

Part of the Bioresource and Agricultural Engineering Commons

Wang, Zheming; Zachara, John M.; Gassman, Paul; Liu, Chongxuan; Qafoku, Odeta; Yantasee, Wassana; and Catalano, Jeff, "Fluorescence spectroscopy of $\mathrm{U}(\mathrm{VI})$-silicates and $\mathrm{U}(\mathrm{VI})$-contaminated Hanford sediment" (2005). US Department of Energy Publications. 257.

https://digitalcommons.unl.edu/usdoepub/257

This Article is brought to you for free and open access by the U.S. Department of Energy at DigitalCommons@University of Nebraska - Lincoln. It has been accepted for inclusion in US Department of Energy Publications by an authorized administrator of DigitalCommons@University of Nebraska - Lincoln. 


\section{Authors}

Zheming Wang, John M. Zachara, Paul Gassman, Chongxuan Liu, Odeta Qafoku, Wassana Yantasee, and Jeff Catalano 


\title{
Fluorescence spectroscopy of U(VI)-silicates and U(VI)-contaminated Hanford sediment
}

\author{
Zheming Wang, ${ }^{1, *}$ John M. Zachara, ${ }^{1}$ Paul L. Gassman,,${ }^{1}$ Chongxuan Liu, ${ }^{1}$ Odeta Qafoku, ${ }^{1}$ Wassana Yantasee, ${ }^{1}$ and \\ JEFF G. CATALANO ${ }^{2}$ \\ ${ }^{1}$ Pacific Northwest National Laboratory, MSIN K8-96, P.O. Box 999, Richland, WA 99352, USA \\ ${ }^{2}$ Stanford University, Stanford, CA 94305, USA
}

(Received November 13, 2003; accepted in revised form August 20, 2004)

\begin{abstract}
Time-resolved U(VI) laser fluorescence spectra (TRLFS) were recorded for a series of natural uranium-silicate minerals including boltwoodite, uranophane, soddyite, kasolite, sklodowskite, cuprosklodowskite, haiweeite, and weeksite, a synthetic boltwoodite, and four U(VI)-contaminated Hanford vadose zone sediments. Lowering the sample temperature from RT to $\sim 5.5 \mathrm{~K}$ significantly enhanced the fluorescence intensity and spectral resolution of both the minerals and sediments, offering improved possibilities for identifying uranyl species in environmental samples. At $5.5 \mathrm{~K}$, all of the uranyl silicates showed unique, well-resolved fluorescence spectra. The symmetric $\mathrm{O}=\mathrm{U}=\mathrm{O}$ stretching frequency, as determined from the peak spacing of the vibronic bands in the emission spectra, were between 705 to $823 \mathrm{~cm}^{-1}$ for the uranyl silicates. These were lower than those reported for uranyl phosphate, carbonate, or oxy-hydroxides. The fluorescence emission spectra of all four sediment samples were similar to each other. Their spectra shifted minimally at different time delays or upon contact with basic $\mathrm{Na} / \mathrm{Ca}$-carbonate electrolyte solutions that dissolved up to $60 \%$ of the precipitated U(VI) pool. The well-resolved vibronic peaks in the fluorescence spectra of the sediments indicated that the major fluorescence species was a crystalline uranyl mineral phase, while the peak spacing of the vibronic bands pointed to the likely presence of uranyl silicate. Although an exact match was not found between the U(VI) fluorescence spectra of the sediments with that of any individual uranyl silicates, the major spectral characteristics indicated that the sediment U(VI) was a uranophane-type solid (uranophane, boltwoodite) or soddyite, as was concluded from microprobe, EXAFS, and solubility analyses. Copyright (C) 2005 Elsevier Ltd
\end{abstract}

\section{INTRODUCTION}

Uranium is a significant contaminant of water and soil at sites of $\mathrm{U}$ mining, milling, and nuclear materials production (Riley and Zachara, 1992; Bernhard et al., 1996; Morris et al., 1996; Bostick et al., 2002); and at environmental locations where $U$ has accumulated through natural geologic or hydrologic processes (Duff et al., 1997; Duff et al., 2000). It is crucial to understand the speciation of $U$ in these settings to understand and predict the future migration behavior of $U$ and to remediate contaminated soils and subsurface sediments.

Environmentally mobile $\mathrm{U}$ exists in the +6 oxidation state as the uranyl cation $\left(\mathrm{UO}_{2}{ }^{2+}\right)$. The geochemistry of the uranyl ion is complex. Uranyl forms a diverse array of aqueous complexes with inorganic and organic ligands. Uranyl is adsorbed extensively by mineral matter through ion exchange to fixed charge sites on phyllosilicates \{smectite, vermiculite, etc. (McKinley et al., 1995; Turner et al., 1996) and by surface complexation to amphoteric surface hydroxyl sites on phyllosilicates (Borovec, 1981; McKinley et al., 1995; Pabalan and Turner, 1996; Thompson et al., 1998; Turner et al., 1996) and $\mathrm{Al}(\mathrm{III}), \mathrm{Fe}(\mathrm{III})$, and Si oxides (e.g., Waite et al., 1994; Hudson et al., 1999; Sylwester et al., 2000). X-ray adsorption spectroscopy measurements have shown that the uranyl cation can adsorb as mononuclear, multinuclear, or oligomeric species (Dent et al., 1992; McKinley et al., 1995; Hudson et al., 1999). Aqueous uranyl-carbonate and phosphate complexes can also adsorb as ternary surface complexes (Bargar et al., 1999, 2000;

* Author to whom correspondence should be addressed (zheming.wang@pnl.gov).
Barnett et al., 2002; Bostick et al., 2002). The uranyl cation exhibits complex crystal chemistry, forming many distinct solid phases with common environmental ligands including hydroxyl, phosphate, silicate, and carbonate (Cejka and Urbanec, 1990; Finch and Ewing, 1991; Morris et al., 1996).

Uranyl displays a unique green-yellow fluorescence emission spectra with vibronic features (Denning, 1992; Bernhard et al., 1996; Meinrath, 1997). For samples with sufficient fluorescence intensity and resolution, identification of uranyl species from its fluorescence spectral signature is possible. This technique has been used to speciate uranium in soils and sediments in combination with X-ray and Raman spectroscopy (Morris et al., 1996; Hunter and Bertsch, 1998; Duff et al., 2000). Metaautunite, phosphuranylite, and uranyl hydroxide (schoepite) were found as the primary U(VI) precipitates in Fernald soil (Hunter and Bertsch, 1998; Morris et al., 1996) while amorphous uranyl hydroxide was the dominant precipitated U(VI) phase at the Savannah River site (Hunter and Bertsch, 1998).

Recently, we obtained a unique set of U(VI)-contaminated samples from beneath a high level waste tank (BX-102) at the U. S. DOE Hanford site that leaked over 7 metric tones of U(VI) into the vadose zone. Leaking tank waste (Bismuth phosphate metal waste) contained high levels of dissolved $\mathrm{U}(\mathrm{VI})$ (ca., $0.3 \mathrm{~mol} / \mathrm{L}$ in the form of a $2.5 \mathrm{~mol} / \mathrm{L} \mathrm{Na}-\mathrm{HCO}_{3}$ solution) that migrated deep into the vadose zone (Fig. 1). We have sought to identify the U species in these sediments with X-ray absorption fine structure (EXAFS), scanning electron microscopy (SEM), X-ray and electron microprobe (XRM, EMP), and laser induced time-resolved fluorescence spectroscopy (LIF) (Catalano et al., 2003; Liu et al., 2004; McKinley et 


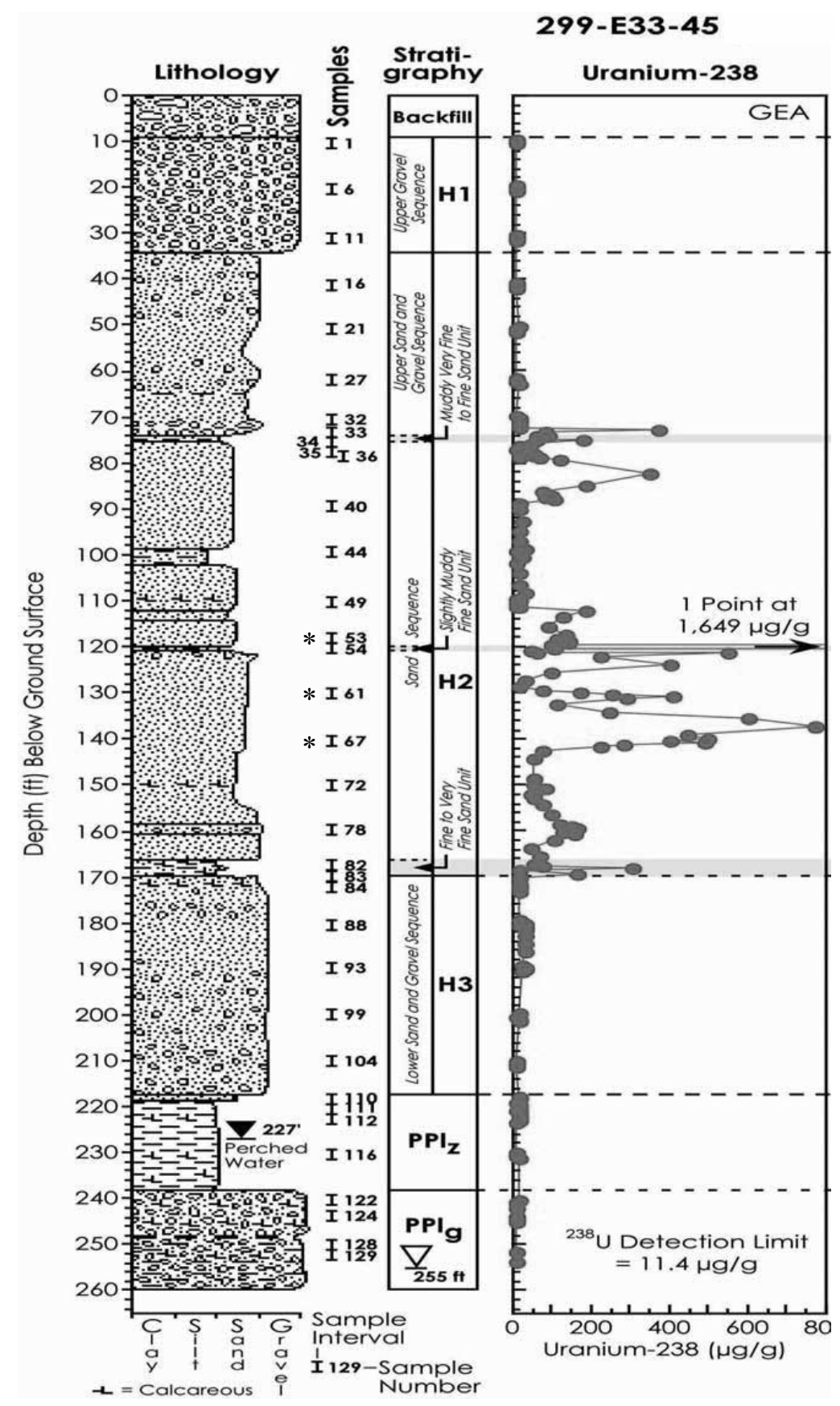

Fig. 1. Depth distribution of U(VI) in borehole 299-E33-45. Sampling locations are marked with an asterisk. Data are from Serne et al. (2002).

al., 2003). EDX analysis of the uranium-bearing grains $(\geq 2$ $\mu \mathrm{m})$ indicated that these sediments are absent of carbon and have an average phosphorus to uranium molar ratio (P:U) of $0.2: 1$. Elements of significance are only oxygen, sodium, aluminum, silicon, potassium, and uranium. Results from EXAFS, SEM, and XRM/EMP measurements suggest that U(VI) exists in the sediments as a uranyl silicate precipitate (Catalano et al., 2003; Liu et al., 2004; McKinley et al., 2003). Initial LIF measurements on the sediments at room temperature (RT) yielded weak and poorly resolved spectra that did not allow identification of the uranyl species. However, cooling the sed- iments to liquid helium temperature (LHeT) significantly enhanced spectral intensity and resolution, providing the ability to speciate precipitated $\mathrm{U}(\mathrm{VI})$ in these subsurface sediments.

In this work, we performed laser induced time-resolved fluorescence spectroscopic measurements on U(VI)-contaminated Hanford sediments at cryogenic conditions (near liquid helium temperature, $5.5 \pm 1.0 \mathrm{~K}$ ) to define the nature and identity of precipitated U(VI) before and after a period of laboratory dissolution. Because a theoretical basis or a predictive relationship does not exist to define the dependence of the fluorescence spectrum of a uranyl compound on its chemical or 
Table 1. Results of X-ray diffraction analysis of uranyl-silicate phases. ${ }^{\text {a }}$

\begin{tabular}{|c|c|c|}
\hline Name & Formula & XRD conclusion \\
\hline Boltwoodite & $\mathrm{K}\left(\mathrm{UO}_{2}\right)\left(\mathrm{SiO}_{3} \mathrm{OH}\right)\left(\mathrm{H}_{2} \mathrm{O}\right)_{15}$ & Good peak agreement with card 13-218. Slight amorphous background. \\
\hline Cuprosklodowskite & $\mathrm{Cu}\left(\mathrm{UO}_{2}\right)_{2}\left(\mathrm{SiO}_{3} \mathrm{OH}\right)_{2}\left(\mathrm{H}_{2} \mathrm{O}\right)_{6}$ & Perfect match to card $8-290$. \\
\hline Kasolite & $\mathrm{Pb}\left(\mathrm{UO}_{2}\right)\left(\mathrm{SiO}_{4}\right)\left(\mathrm{H}_{2} \mathrm{O}\right)$ & Good match to cards $12-210$ and $29-788$. \\
\hline Sklodowskite & $\mathrm{Mg}\left(\mathrm{UO}_{2}\right)_{2}\left(\mathrm{SiO}_{3} \mathrm{OH}\right)_{2}\left(\mathrm{H}_{2} \mathrm{O}\right)_{6}$ & Highly crystalline sample, close match to database (card 29-875). \\
\hline Soddyite & $\left(\mathrm{UO}_{2}\right)_{2}\left(\mathrm{SiO}_{4}\right)\left(\mathrm{H}_{2} \mathrm{O}\right)_{2}$ & $\begin{array}{l}\text { A } 50 / 50 \text { mixture of soddyite (card 35-0491) and curite } \\
{\left[\mathrm{Pb}_{1.5+\mathrm{x}}\left(\mathrm{UO}_{2}\right)_{6} \mathrm{O}_{4+2 \mathrm{x}}(\mathrm{OH})_{3-2 \mathrm{x}}\left(\mathrm{H}_{2} \mathrm{O}\right)\right]}\end{array}$ \\
\hline Uranophane & $\mathrm{Ca}\left(\mathrm{UO}_{2}\right)_{2}\left(\mathrm{SiO}_{3} \mathrm{OH}\right)_{2}\left(\mathrm{H}_{2} \mathrm{O}\right)_{5}$ & XRD pattern matched well with database (card 39-1360). \\
\hline Haiweeite & $\mathrm{Ca}\left(\mathrm{UO}_{2}\right)_{2}\left[\mathrm{Si}_{5} \mathrm{O}_{12}(\mathrm{OH})_{2}\right]\left(\mathrm{H}_{2} \mathrm{O}\right)_{3}{ }^{\mathrm{b}}$ & $\begin{array}{l}\text { This sample is predominantly calcite with minor haiweeite }(10-25 \%) \\
\text { (cards } 22-160,13-118 \text {, and 12-721). }\end{array}$ \\
\hline Synthetic Boltwoodite & $\mathrm{K}\left(\mathrm{UO}_{2}\right)\left(\mathrm{SiO}_{3} \mathrm{OH}\right)\left(\mathrm{H}_{2} \mathrm{O}\right)_{15}$ & Perfect match with card 35-0490. \\
\hline Weeksite & $\mathrm{K}_{2}\left(\mathrm{UO}_{2}\right)_{2}\left(\mathrm{Si}_{2} \mathrm{O}_{5}\right)_{3}\left(\mathrm{H}_{2} \mathrm{O}\right)_{4}^{\mathrm{c}}$ & The sample quantity was too small for XRD analysis. \\
\hline
\end{tabular}

a The mineral formulae were taken from reference Finch and Murakami (1999) or noted otherwise.

b Data from Burns (2001).

${ }^{\mathrm{c}}$ Data from Vochten et al. (1997a).

crystal structure, LIF measurements were performed on a series of natural and synthetic U(VI) silicates to provide spectral reference. Direct comparisons were made between the spectral signatures of the reference minerals to those in the sediments acquired under the same experimental conditions. These comparisons, along with other measurements, implied the presence of boltwoodite or uranophane in the sediments. These phase identifications were generally consistent with those made by other techniques (e.g., Catalano et al., 2003). However, compositional information from EMP analysis was necessary to identify plausible U(VI)-silicate candidate phases that often did not differ significantly in their fluorescence emission spectra.

\section{EXPERIMENTAL}

\subsection{Uranium Silicate Minerals}

Nine natural uranium-silicate minerals were obtained from the American Museum of Natural History (AMNH) and the Smithsonian Institution (SI) (Table 1). The natural weeksite was provided by professor Peter Burns at The University of Notre Dame, Notre Dame, Indiana. Synthetic boltwoodite was supplied by Dr. S.B. Clark at Washington State University, Pullman, Washington. The synthetic boltwoodite was prepared by reacting $0.35 \mathrm{~g} \mathrm{UO}_{2}\left(\mathrm{NO}_{3}\right)_{2} \cdot 6 \mathrm{H}_{2} \mathrm{O}, 0.5 \mathrm{~g}$ $\mathrm{KCl}$ and $3 \mathrm{~g}$ hydrothermal quartz in $25 \mathrm{~mL} \mathrm{H}_{2} \mathrm{O}$ at $\mathrm{pH} 11.5$ in a Parr reaction bomb at $180^{\circ} \mathrm{C}$ for $7 \mathrm{~d}$ following the procedure of Vochten et al. (1997b). The mineral samples consisted of fine-grained crystallites ranging in size from tens of microns to more than one millimeter. The minerals were analyzed by X-ray diffraction (XRD) to confirm their identity. Some of the natural specimens contained lithic fragments of quartz, or calcite. XRD and fluorescence analyses were performed on the yellow/greenish U-mineralization zones only.

\subsection{Hanford Vadose Zone Sediment Samples}

Four U-contaminated Hanford vadose zone sediment samples, 53A, $61 \mathrm{~A}, 61 \mathrm{AB}$, and $67 \mathrm{AB}$ were studied by LIFS. These samples were obtained from Hanford borehole 299-E33-45 that was placed through a metal waste plume proximate to Tank BX-102 in 2001 to provide information on the depth distribution and inventory of uranium and technetium resulting from the 1951 spill (RPP-10098, 2002; Womack and Larkin, 1971). The samples were obtained from depths of 118.8, 130.7, and $141.0 \mathrm{ft}$ below ground surface, respectively (Fig. 1 and Table 2).

Samples $61 \mathrm{AB}$ and $67 \mathrm{AB}$ were subjected to a period of desorption/ dissolution in the following electrolytes: i.) $\mathrm{NaHCO}_{3}(0.194 \mathrm{mM})-$ $\mathrm{NaNO}_{3}(0.0498 \mathrm{M})$ with $\mathrm{I}=0.05, \mathrm{pH} 7.27$, and contact time of 4 weeks; ii.) $\mathrm{NaHCO}_{3}(15.59 \mathrm{mM})-\mathrm{Na}_{2} \mathrm{CO}_{3}(4.93 \mathrm{mM})-\mathrm{NaNO}_{3}(0.0245$ $\mathrm{M})$ with $\mathrm{I}=0.05$, pH 9.25, and contact time of 4 weeks; iii.) $\mathrm{CaCO}_{3(\mathrm{~s})^{-}}$ saturated $\mathrm{Ca}\left(\mathrm{ClO}_{4}\right)_{2}(0.0219 \mathrm{M})-\mathrm{NaClO}_{4}(0.0666 \mathrm{M})$ with $\mathrm{I}=0.05, \mathrm{pH}$ 7.57, and contact time of 2 weeks; and iv.) $\mathrm{CaCO}_{3(\mathrm{~s})}$-saturated $\mathrm{NaClO}_{4}(0.0416 \quad \mathrm{M})-\mathrm{NaHCO}_{3} \quad(4.44 \quad \mathrm{mM})-\mathrm{Na}_{2} \mathrm{CO}_{3} \quad\left(\begin{array}{lll}4.44 & \mathrm{mM}\end{array}\right)-$ $\mathrm{HClO}_{4}(1.425 \mathrm{mM})$ with $\mathrm{I}=0.05, \mathrm{pH} 8.96$, and contact time of 2 weeks. These solutions are hereafter abbreviated as Na-1, Na-2, Ca-1 and Ca-2. The sediments were slowly shaken continuously with the electrolytes at room temperature using a solid to solution ratio of 200 $\mathrm{g} / \mathrm{L}$. An aliquot of the suspension was withdrawn after the desired contact time and the sediment and the solution were separated by filtration (prewashed Centriplus YM-30 centrifugal device filters). Both the leached solids and the supernatant were analyzed by LIFS.

\subsection{XRD Measurements}

Powder diffraction (XRD) measurements were performed using $\mathrm{Cu}$ $\mathrm{K}_{\alpha}$ radiation $(\lambda=1.5418 \AA)$ on a Rigaku X-ray diffractometer at Stanford University. Data were analyzed using the software package Jade 6.5 (Materials Data, Inc., Livermore, California). XRD patterns were compared with the Powder Diffraction File (PDF) to determine the phase(s) present. Initial comparisons were done using an automated search/match routine. These results were combined with direct comparison of the PDF patterns of likely uranium-bearing and accessory (e.g., quartz, calcite) phases to determine the qualitative sample compositions.

\subsection{Cryogenic U(VI) Fluorescence Measurements}

Fluorescence spectroscopic and lifetime measurements were performed in a Cryo Industries RC-152 cryostat at near liquid He-temperature $(5.5 \pm 1.0 \mathrm{~K})$. Individual solid samples were mounted in custombuilt sealed copper sample holders fitted with sapphire optical windows. Solution samples $(\sim 100 \mu \mathrm{L})$ were transferred into a $3 \mathrm{~mm}$ x $3 \mathrm{~mm}$ quartz spectroscopic cell fitted with silicone stoppers. Atmosphere control was maintained throughout the sample handling procedure except during the spectral acquisition for the solution samples. The samples were attached to the cold finger of a Cryo Industries RC-152 cryogenic workstation in which the sample cell was directly exposed to the vapor flow of liquid helium. The sample temperature

Table 2. U(VI)-contaminated Hanford sediments collected proximate to BX-102.

\begin{tabular}{llcc}
\hline & Label & $\begin{array}{c}{[\mathrm{U}]} \\
(\mu \mathrm{g} / \mathrm{g})\end{array}$ & $\begin{array}{c}\text { Depth in the sample core } \\
(\mathrm{ft} \mathrm{bg})\end{array}$ \\
\hline No. & $53 \mathrm{~A}$ & 142 & $118.79-119.29$ \\
1 & $61 \mathrm{~A}$ & 415 & $130.70-131.20$ \\
3 & $61 \mathrm{AB}$ & 404 & $130.70-131.20$ \\
4 & $67 \mathrm{AB}$ & 327 & $141.00-141.50$ \\
\hline
\end{tabular}


was controlled by tuning both the liquid helium flow rate and the electric current applied to the internal heater of the cryostat through a Lakeshore 330 auto-tuning temperature controller. The normal fluorescence emission spectra of samples were obtained by excitation at 415 $\mathrm{nm}$, the spectral maximum of the first electronic absorption band, by the frequency doubled output of a Spectra-Physics Nd:YAG laser pumped MOPO-730 laser. The resulting fluorescence was collected at $75^{\circ}$ to the excitation beam by a 2 in diameter $f / 3$ fused silica lens and focused by a 2 inch $\mathrm{f} / 4$ fused silica lens into the entrance slit of a $0.3 \mathrm{~m}$ focal length Acton SpectroPro 300i double monochromator spectrograph. An Omega 460LP cutoff filter with a cutoff wavelength of 460 $\mathrm{nm}$ was placed in front of the entrance slit of the spectrograph to reject the scattered laser light.

Time-resolved emission spectra were recorded using a thermoelectrically cooled Princeton Instruments PIMAX time-gated intensified CCD camera that was triggered by the delayed output of the laser pulse and controlled by the WinSpec data acquisition software. The same sample volume and geometry was used for all analyses to allow semiquantitative and/or quantitative determination of uranyl species. The fluorescence lifetime of U(VI) in the samples was measured by excitation with the frequency-doubled output of a Pulsed Nd:YAG laser pumped MOPO laser system $(415 \mathrm{~nm})$. The light emitted by the sample was collected at $90^{\circ}$ by an $\mathrm{f} 1.5$ fused silica lens and detected by a Hamamatsu R928 photomultiplier tube (PMT) at wavelength between $490 \mathrm{~nm}$ to $550 \mathrm{~nm}$ after dispersing through a CVI R110 monochromator. The fluorescence intensity signal from the PMT was amplified and recorded with a Tektronics TDS 754A digital oscilloscope.

Data analysis was performed using the IGOR, a commercial software, and the Globals program (Beechem et al., 1991).

\section{RESULTS}

\subsection{XRD Analysis of Uranium-Silicate Minerals}

Most of the U(VI)-silicates were of high purity and crystallinity with XRD patterns that were consistent with literature reports (Table 1). A few samples turned out to be impure: the "soddyite" was a 50/50 mixture of soddyite and curite and the haiweeite was predominantly calcite, with minor haiweeite (10\%-25\%). Uranophane and boltwoodite contained a small amount of amorphous materials. Representative diffraction patterns for uranophane, boltwoodite, and soddyite are shown in Figure 2.

\subsection{Room Temperature and Cryogenic Fluorescence Spectroscopic Characterization of Uranium Silicate Minerals}

The fluorescence emission spectra of the uranyl silicates showed large variability at room temperature (Fig. 3). The fluorescence spectral characteristics of those samples containing nonfluorescence minerals such as calcite and quartz reflect only that of the uranium mineral present, albeit at lower intensity. Boltwoodite (both synthetic and natural), uranophane and haiweeite showed relatively strong, well-resolved emission spectra with typical vibronic characteristics of uranyl. The soddyite and weeksite showed broad spectra spanning the wavelength region typical of uranyl compounds. Cuprosklodowskite, sklodowskite and kasolite, all containing another divalent metal in their crystal structure, were nearly without fluorescence. The room temperature measurements demonstrated that the fluorescence spectra of uranyl silicates were dependent on sample composition.

Lowering the sample temperature increased both the fluorescence spectral intensity and the resolution. While these enhancements were experienced within the entire temperature range investigated $(\mathrm{RT}-5 \mathrm{~K})$, a dramatic resolution enhance- ment was often observed between $40 \mathrm{~K}$ to $10 \mathrm{~K}$, corresponding to the suppression of phonon-assisted energy transfer. At nearliquid helium temperature, all of the uranyl silicates showed bright green-yellow fluorescence upon laser excitation $\left(\lambda_{\mathrm{ex}}=\right.$ $415 \mathrm{~nm}$ ) (Fig. 4). However, the relative fluorescence intensity increase varied by over three orders of magnitude for the different phases. Uranophane exhibited a 10-fold fluorescence intensity increase while the others were 100 to 1000 times more fluorescent. These results indicated that the composition and structure of the uranyl silicate dictate the fluorescence spectral characteristics in the absence of fluorescence quenching.

Differences were observed in the fluorescence emission spectra of the natural boltwoodite and a synthetic form (Vochten et al., 1997b) (Fig. 4). One possible explanation for the differences is a variation in degree of hydration, which can vary with paragenesia and synthesis conditions (Morris et al., 1996).

The fluorescence spectra (Fig. 4) agreed with the XRD analyses, confirming the presence of mineral mixtures in some cases, and single phases in others. XRD analyses of soddyite from AMNH indicate that the sample is a mixture of curite and soddyite. However, time resolved fluorescence spectra at $5.5 \mathrm{k}$ temperature showed that soddyite had a longer fluorescence lifetime than curite. As the delay time was increased the curite spectra decayed after $\sim 500 \mu$ s, leaving only that of the soddyite (Fig. 5).

Uranyl compounds exhibit characteristic fluorescence spectral features including vibronic bands with defined peak spacing and relative intensities, band origins, and fluorescence lifetimes. The peak spacing (Table 3) between the vibronic bands corresponds to the symmetric stretching of the $\mathrm{O}=\mathrm{U}=$ $\mathrm{O}$ entity, $\nu_{1}$. The enhanced spectral resolution obtained by low

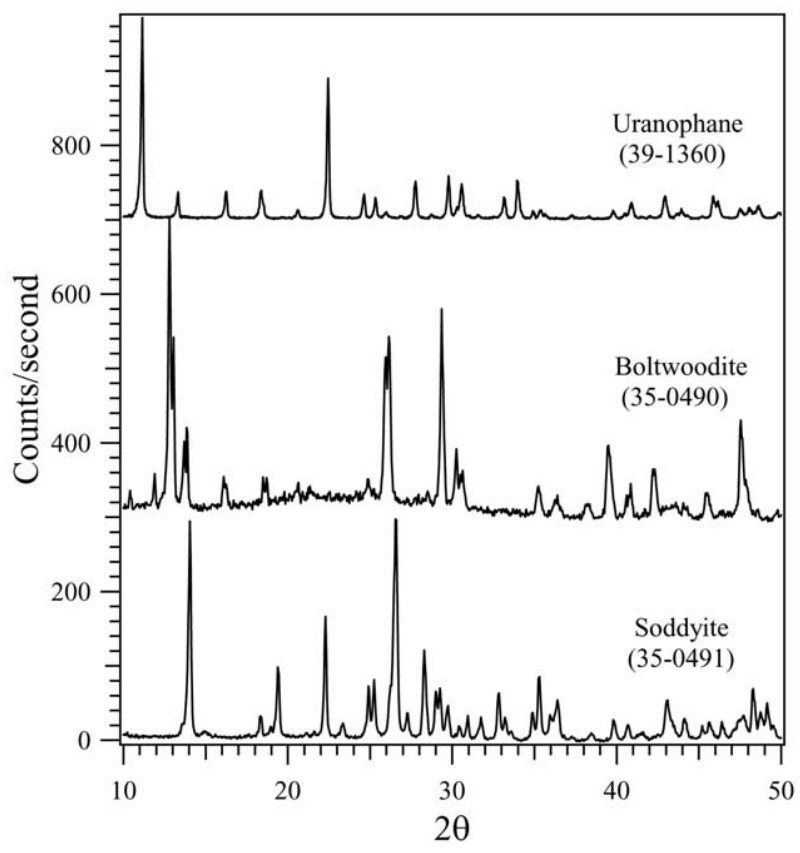

Fig. 2. Representative XRD patterns (soddyite, boltwoodite and $\beta$-uranophane). 


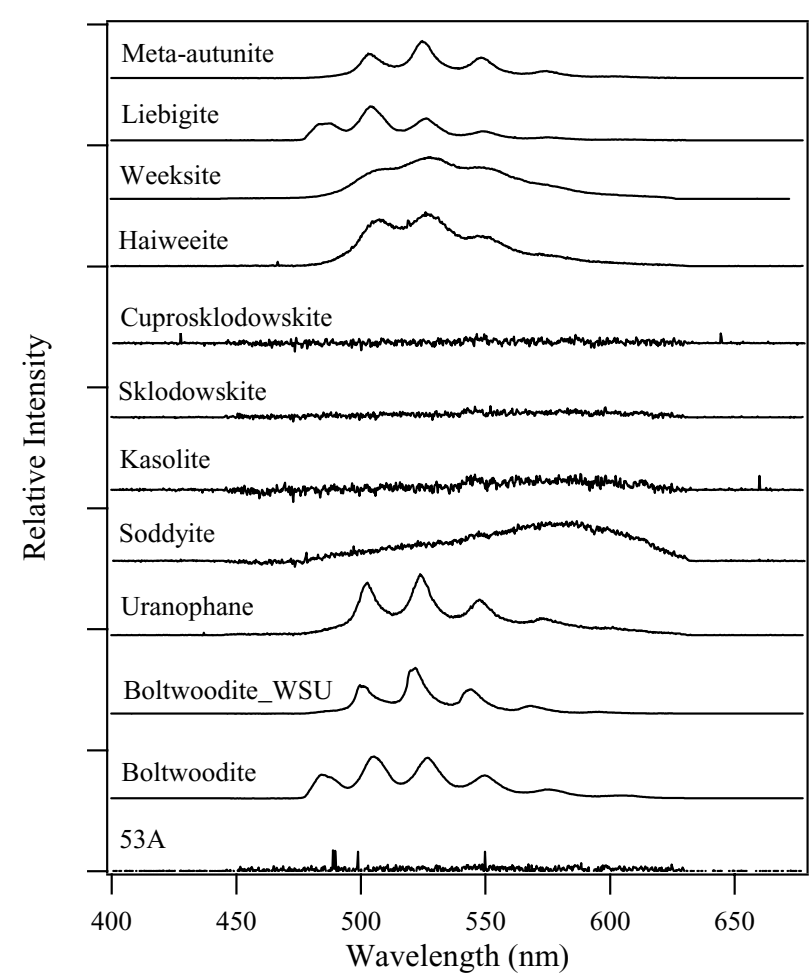

Fig. 3. Fluorescence spectra of uranyl silicates and Hanford sediment (53A) at room temperature. $\lambda_{\mathrm{ex}}=415 \mathrm{~nm}$.

temperature measurement made it possible to calculate $\nu_{1}$ for all of the uranyl silicates. The band origin is the highest vibronic band resulting from the electronic emission from the $\mathrm{v}$ $=0$ (lowest) vibrational state of the excited state to the $\mathrm{v}=0$ vibrational state of the ground state. Although classical symmetry-based analysis of the vibrational progression has been attempted, the presence of multiple electronic transitions (Brittain and Perry, 1980) and many vibrational modes in the spectral region make it impossible to predict the relative intensities of the vibronic bands.

Uranyl silicates showed short fluorescence lifetimes at room temperature (Table 3) as compared to the uranyl phosphates and carbonates (Bernhard et al., 1996; Geipel et al., 2000; Wang et al., 2003). Among the uranyl silicates, only boltwoodite and uranophane showed fluorescence lifetimes longer than a few microseconds while the rest were all less than $1 \mu$ s. Fluorescence lifetimes became much longer at liquid helium temperatures (Table 3) which is consistent with the changes in fluorescence spectra. The decrease in fluorescence quenching that occurs at low temperature enhances fluorescence emission and leads to longer fluorescence lifetimes.

Fluorescence decay of all the uranyl silicates was described with two exponential functions (Fig. 6). Bi-exponential decay behavior is commonly observed for U(VI) minerals at cryogenic temperatures, but the phenomenon has not been well explained. Volodko et al. (1974) postulated that a redistribution of energy occurs after excitation and that two geometrically similar coordination environments develop for the mineral species (Brittain and Perry, 1980).

\subsection{Fluorescence Spectral Analysis of the BX-102 Sediment Samples}

The U-contaminated Hanford sediments displayed only broad and weak fluorescence spectra at room temperature (Fig. 7), which were useless for the identification of uranium species. Because the sediment concentrations of U(VI) were relatively high (Table 2), the weak, broad fluorescence spectra indicated the presence of U(VI) fluorescence quenchers or multiple uranium phases, structures, or compositions that could facilitate energy transfer between the uranium species or with the host sediment.

Lowering the sample temperature dramatically increased the fluorescence intensity (two to three orders of magnitude) and spectral resolution (Fig. 7). Liquid nitrogen temperatures ( $\mathrm{LN}-77 \mathrm{~K})$ were insufficient to achieve desired spectral resolution (Fig. 7b). Optimal enhancement was achieved upon cooling to near liquid helium temperature (Fig. 7c). As observed for some of the uranyl silicates, spectral sharpening of the sediment samples was dramatic when the sample temperature decreased from $\sim 50 \mathrm{~K}$ to $\sim 10 \mathrm{~K}$. Spectral changes were minimal below $10 \mathrm{~K}$.

The four U-contaminated sediments, though acquired at three distinct depths (Table 2) exhibited nearly identical spectral profiles (Fig. 8, Table 4). The spectra of all four sediments consisted of sharp, well-resolved vibronic peaks characteristic of uranyl compounds emanating from a weak, broad fluorescence background. Fluorescence measurements indicated the

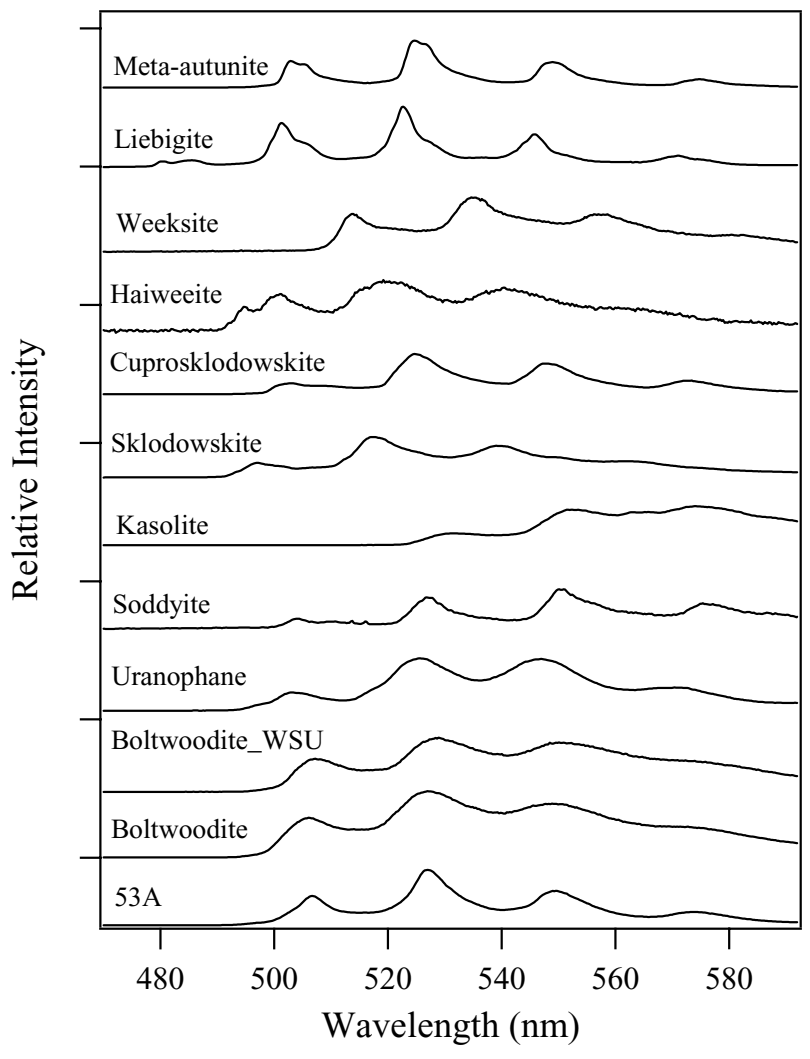

Fig. 4. Fluorescence spectra of uranyl silicates and Hanford sediment (53A) at $6 \mathrm{~K} . \lambda_{\mathrm{ex}}=415 \mathrm{~nm}$. 


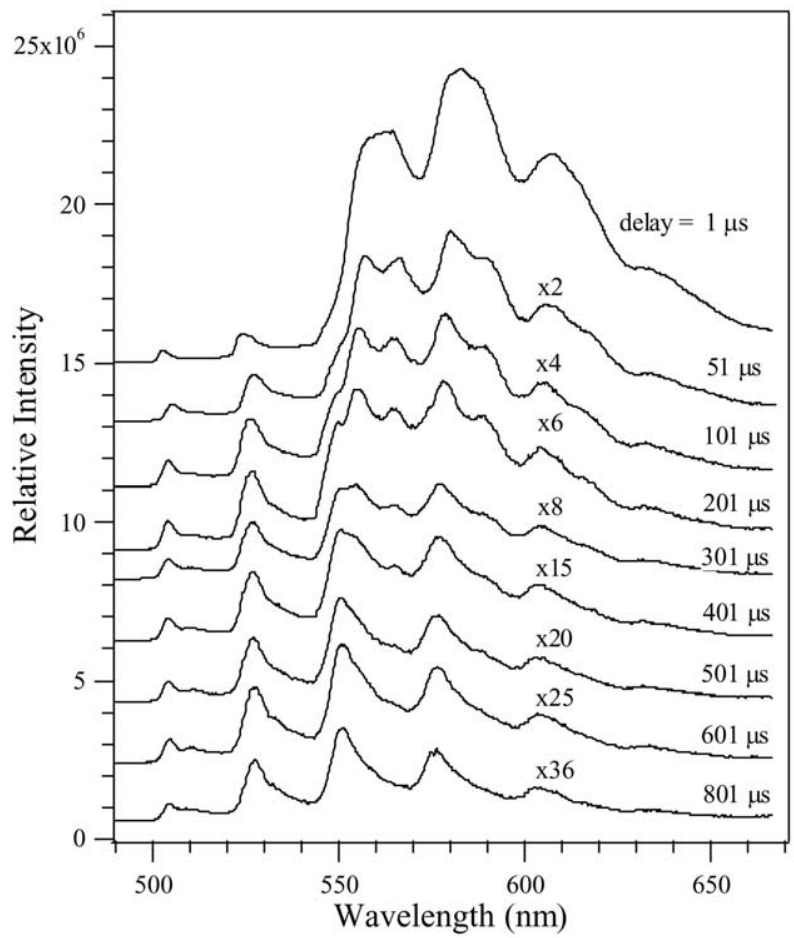

Fig. 5. Time-resolved fluorescence spectra of a mixture of soddyite and curite at $6 \mathrm{~K} . \lambda_{\mathrm{ex}}=415 \mathrm{~nm}$.

presence of a dominant, single uranyl species, or a limited number of uranyl species with similar fluorescence behavior. The appearance of a weak, broad spectral background implied the presence of coexisting minor species such as adsorbed surface complexes or an amorphous uranyl compound. The spectra were nearly invariant at time delays from $1 \mu$ s to 801 $\mu \mathrm{s}$, nearly five times the fluorescence lifetimes of these sediments (Fig. 9). Fluorescence lifetimes (Table 4) varied little among the four sediments, again implying the presence of a common U(VI) phase.

Emission peak spacings of the sediment U(VI) phase ranged between $761 \mathrm{~cm}^{-1}$ and $782 \mathrm{~cm}^{-1}$ (Table 4). These spacings were small compared to the aqueous uranyl ion $\left(872 \mathrm{~cm}^{-1}\right)$ or those of U(VI)-carbonate and U(VI)-phosphate minerals (Mor- ris et al., 1994, 1996; Geipel et al., 2000; Wang et al., 2003). These peak spacings suggest weakened apical $\mathrm{U}=\mathrm{O}$ bonds as a result of stronger interaction between the equatorial ligands and U(VI).

\subsection{Spectral Analysis of Sediments Subjected to Dissolution}

The fluorescence spectra of the U(VI)-contaminated sediments equilibrated in $\mathrm{Na}$ and $\mathrm{Ca}$ electrolytes were measured to ascertain whether the spectral signature changed after leaching/ solubilizing a portion of the precipitated U(VI) pool. A comparison of the spectra of the original and equilibrated sediment samples indicated that electrolyte contact and partial solubilization did not markedly change the spectral characteristics of the residual U(VI) phase (Figs. 10 and 11, Table 4). The fluorescence intensity of the sediment decreased in direct proportion to the quantity of U(VI) solubilized, within the error limit of the measurement. This was a mass loss effect. Solubilization increased with the increasing $\mathrm{pH}$ and carbonate content of the electrolyte solution (Liu et al., 2004). The solubilization extent also differed between the sediments.

The fluorescence spectra of U(VI) leached into the electrolyte solutions were significantly different from those of the sediment U(VI) (Fig. 12, Table 4). All of the vibronic peaks of the aqueous complexes were blue-shifted and the bandwidth increased as compared to the precipitated phase. The relative spectral intensities were larger in both $\mathrm{Na}$ and $\mathrm{Ca}$ electrolytes at higher $\mathrm{pH}$ (e.g., $\mathrm{Na}-2$ and $\mathrm{Ca}-2)$, because of the increased solubility of U(VI) in the sediment (Liu et al., 2004). Comparison of the fluorescence spectra of $\mathrm{U}(\mathrm{VI})$ in the $\mathrm{Na}-$ and $\mathrm{Ca}-\mathrm{HCO}_{3}$ electrolyte solutions to those of the $\mathrm{UO}_{2}\left(\mathrm{CO}_{3}\right)_{2}{ }^{2-}$, $\mathrm{UO}_{2}\left(\mathrm{CO}_{3}\right)_{3}{ }^{4-}$ and $\mathrm{Ca}_{2} \mathrm{UO}_{2}\left(\mathrm{CO}_{3}\right)_{3}$ complexes (Wang et al., 2004) indicated these complexes had formed during dissolution of sediment $\mathrm{U}(\mathrm{VI})$. It was not possible to spectroscopically ascertain which of these complexes was dominant in the aqueous phase of the sediment suspensions because their spectra are similar. Thermodynamic calculations, based on solution composition, indicated that the tricarbonate complex should be dominant.

Table 3. Fluorescence spectral characteristics of standard natural uranium silicate minerals $\lambda_{\mathrm{ex}}=415 \mathrm{~nm}$

\begin{tabular}{|c|c|c|c|c|c|}
\hline Mineral & Spectral maxima (nm) & $\begin{array}{c}\nu_{1}(\mathrm{f}) \\
\left(\mathrm{cm}^{-1}\right)\end{array}$ & $\begin{array}{l}\nu_{1}(\mathrm{vib})^{\mathrm{a}} \\
\left(\mathrm{cm}^{-1}\right)\end{array}$ & $\tau$ at R.T. & $\begin{array}{c}\tau \text { at LHeT. } \\
(\mu \mathrm{s})\end{array}$ \\
\hline Boltwoodite & $505.4,535.2,558.0,579.4$ & 760 & 787 & $7.4,0.9$ & 266,53 \\
\hline Synthetic boltwoodite & $505.86,526.86,549.15 .-^{\mathrm{c}}$ & 779 & $-^{\mathrm{b}}$ & $4.8,2.8$ & 322,107 \\
\hline Cuprosklodowskite & $502.9,524.7,547.5,573.5$ & 816 & 777 & $1.0,0.1$ & 196,52 \\
\hline Kasolite & $-^{\mathrm{c}}, 531.2,552.2,574.2$ & 705 & $-{ }^{b}$ & $0.6,0.1$ & 25,5 \\
\hline Sklodowskite & $496.6,516.7,538.7,561.5$ & 776 & 763 & $0.7,0.3$ & 207,48 \\
\hline Soddyite & $504.5,527.4,551.0,576.3$ & 823 & 832 & $0.6,0.2$ & 300,47 \\
\hline Uranophane & $503.1,525.5,547.0,570.5$ & 783 & 790 & $4.6,0.7$ & 192,51 \\
\hline Haiweeite & $494.7,501.0,519.2,540.1,-^{\mathrm{c}}$ & 722 & - & $-\mathrm{b}$ & 246,73 \\
\hline Weeksite & $513.8,535.0,558.6,582.6$ & 766 & $865-877$ & $10.4,1.0$ & 134,21 \\
\hline
\end{tabular}

a Data from Cejka (1999).

${ }^{\mathrm{b}}$ Data unavailable.

${ }^{c}$ An accurate value cannot be obtained because of weak intensity or spectral overlap. 

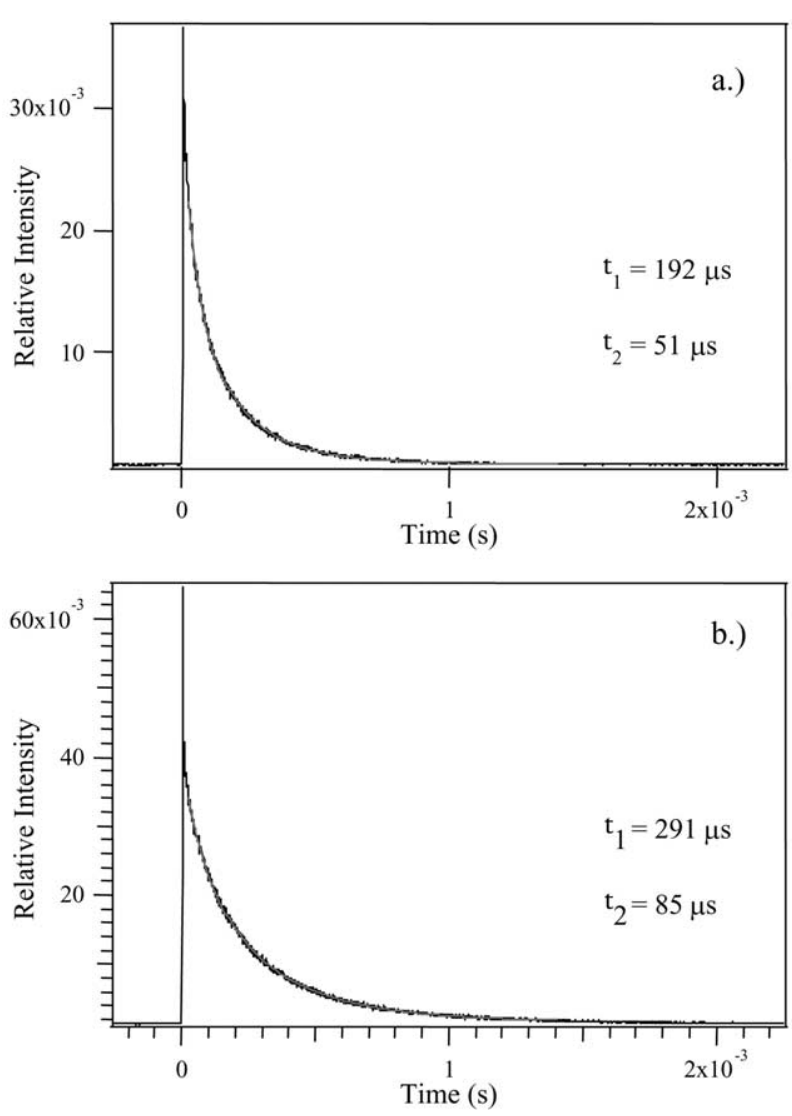

Fig. 6. Representative fits of the fluorescence decay of uranophane (a) and Hanford sediment 53A (b) at LHeT. $\lambda_{\mathrm{ex}}=415 \mathrm{~nm}$.

\section{DISCUSSION}

\subsection{Spectral Enhancement at Cryogenic Temperatures}

Most of the uranyl silicates and all of the U-bearing sediments exhibited weak and poorly resolved fluorescence emission spectra at room temperature (Figs. 3 and 7), despite the relatively high uranium concentration in these solids (Tables 1 and 2). Since $U(V I)$ is a known green-yellow fluorophore, the observed weak fluorescence suggests the presence of fluorescence quenching mechanisms in the samples. As temperature was lowered, all of the $\mathrm{U}(\mathrm{VI})$ silicates and the sediments showed intense, well resolved fluorescence spectra between $490 \mathrm{~nm}$ and $650 \mathrm{~nm}$ (Figs. 4, 7 and 8). This confirmed that at room temperature sample fluorescence was quenched and thermally broadened. It also indicated that quenching and spectral broadening effect(s) were largely removed at liquid helium temperature.

There are many mechanisms leading to the quenching of uranyl fluorescence. Some, such as coupling with high energy vibrational modes of solvents, resonance energy transfer to ions and molecules with energy levels close to that of the uranyl excited state, phonon coupling, energy transfer to defect centers in solids, concentration quenching, and heavy metal effects are common to many fluorophores (Rabinowitch and Belford, 1964; Lakowicz and Weber, 1973; Baird and Kemp, 1997). It is well known that vibrational and phonon-coupling lead to spectral broadening (Jankowiak and Small, 1989). The U(VI) ion exhibits several additional fluorescence quenching mechanisms because of its large oxidizing potential $\left(\mathrm{E}^{0}=2.6 \mathrm{~V}\right.$ (Balzani et al., 1978; Burrows et al., 1985; Burrows and Miguel, 2001) and the long lifetime of its excited state. These mechanisms include photo-reduction by organic and inorganic molecules, hydrogen atom abstraction (Moriyasu et al., 1977), and electron transfer from other metal ions (Burrows et al., 1975; Marcantonatos, 1979a,b; Azenha et al., 1989). Potentially, any of these mechanisms may have occurred in the sediment samples due to low concentrations of transition metal and lanthanide contaminants.

For uranyl compounds, the spectral intensity and resolution enhancement at lower temperatures was noticed as early as 1909 by Becquerel et al. $(1909,1910)$. They cooled solid uranyl salts to liquid air temperature $(90 \mathrm{~K})$, and observed the disappearance, splitting, and sharpening of spectral bands. The spectral bands of some uranyl salts were further sharpened at the temperature of liquid nitrogen. Later, Samojlov (1948) noted that cooling from $90 \mathrm{~K}$ (liquid air) to $4.2 \mathrm{~K}$ (liquid helium) caused further spectral narrowing and splitting with corresponding line shifts of $5-12 \mathrm{~cm}^{-1}$ towards shorter wavelengths. Now it is generally understood that the fluorescence spectra of pure uranyl compounds originates from the electronic transition from the first excited state to the ground state coupled with various vibrational transitions either at ground state or excited state. The main vibrational state involved is the symmetric $\mathrm{O}=\mathrm{U}=\mathrm{O}$ stretching mode; coupling to this mode leads to the approximately evenly spaced emission bands in the blue to yellow spectral range. However, there are also simultaneous coupling with, i.) other vibrational modes such as the antisymmetric stretching mode and the bending mode of uranyl, ii.) vibrational modes of the associated anions and water molecules, and iii.) the crystal lattice. It is the suppression of

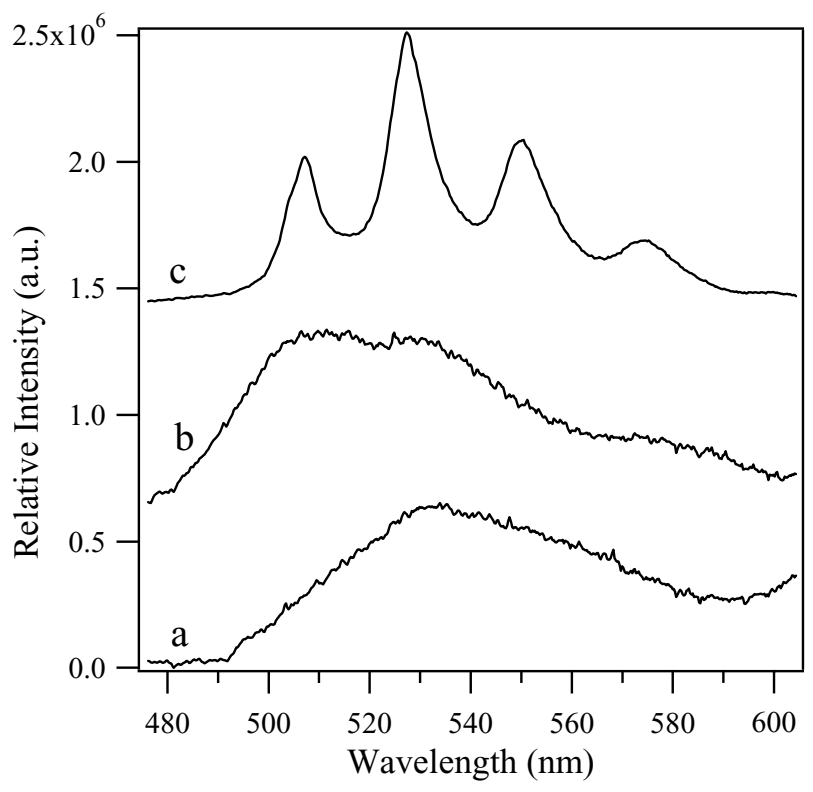

Fig. 7. Fluorescence emission spectra of Hanford vadose zone sediment 53A at different temperatures. (a) RT; (b) $77 \mathrm{~K}$; and (c) LHeT. $\lambda_{\mathrm{ex}}=415 \mathrm{~nm}$. 


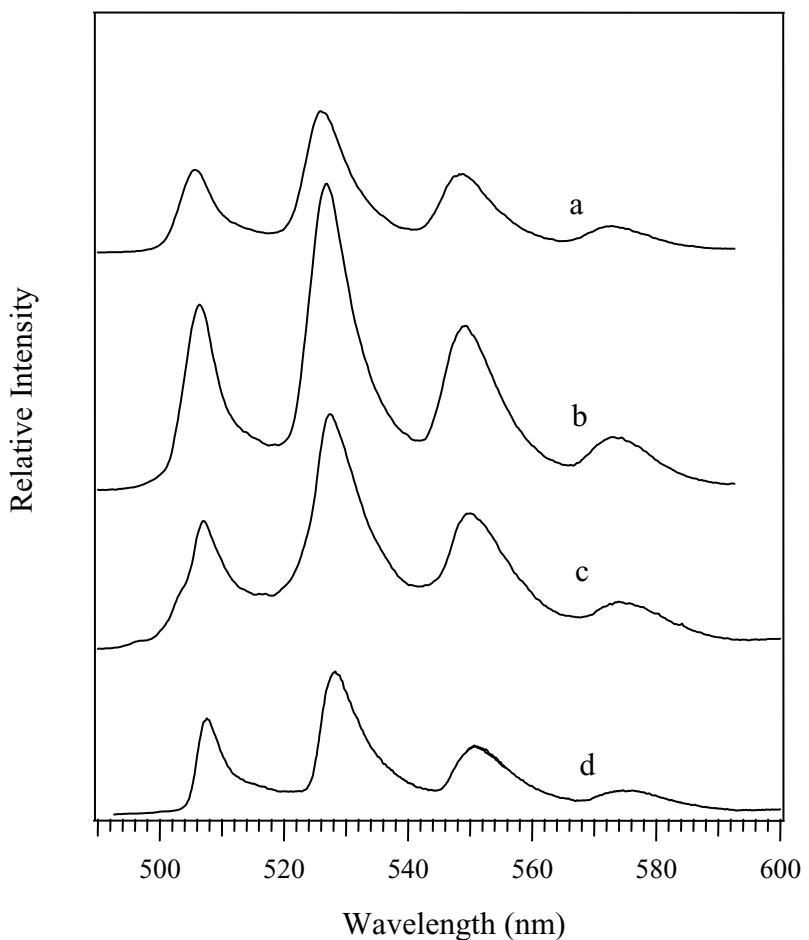

Fig. 8. Fluorescence emission spectra of Hanford sediments at $5.5 \mathrm{~K}$ (a) $53 \mathrm{~A}$; (b) $61 \mathrm{AB}$; (c) $67 \mathrm{AB}$; and (d) $61 \mathrm{~A}$. $\lambda_{\text {ex }}=415 \mathrm{~nm}$.

the latter modes that increased both the spectral intensity and resolution (Rabinowitch and Belford, 1964).

Low temperature spectral enhancement has been used for speciation studies of $\mathrm{U}(\mathrm{VI})$ sorption complexes on mineral oxides and in contaminated soils and sediments (Duff et al., 2000). The presence of multiple uranyl binding sites on $\alpha$-alumina was confirmed by fluorescence measurements at $77 \mathrm{~K}$ (Burrows et al., 1986). The 1:4 and 1:5 uranyl hydrolysis products were measured using $77 \mathrm{~K}$ fluorescence measurements (Clark et al., 1999) in strong base. Duff et al. (2000) demonstrated that the spectral resolution of U(VI) in contaminated sediments when the temperature was decreased from RT to $77 \mathrm{~K}$.

\subsection{Fluorescence Characteristics of Uranium Silicate Minerals}

The large variations of the fluorescence spectra among the minerals indicate that ligand coordination in the equatorial position of the $\mathrm{UO}_{2}{ }^{2+}$ cation influences its fluorescence properties. The vibronic peak spacings for the uranyl silicates, $\nu_{1}$, were between 705 to $823 \mathrm{~cm}^{-1}$ (Table 3), consistent with those reported from IR and Raman spectra (Cejka, 1999). These $\nu_{1}$ values were smaller than those reported for uranyl phosphates and carbonates (Geipel et al., 2000; Wang et al., 2003), arsenates (Geipel et al., 2000), and chlorides (Flint and Tanner, 1978). A strong chemical interaction is therefore implied between uranyl and silica because increased binding strength in the equatorial plane withdraws electron density from the apical oxygens and thus reduces the strength of the $\mathrm{U}=\mathrm{O}$ bonds. The strong binding between uranyl and silica may reflect acid-base hardness. The total acid dissociation constant, $\Sigma \mathrm{pKa}$, is a qualitative measure of the basisity of a conjugate acid anion. The $\Sigma$ pKa for silicic acid is 45.36 , as compared to 16.62 for carbonic acid and 20.88 for phosphoric acid. As a hard acid, uranyl binds more strongly with a hard base such as the silicate anion (Pearson, 1963).

There were some variations in $\nu_{1}$ between the different uranyl silicates: those of cuprosklodowskite and soddyite were greater than $800 \mathrm{~cm}^{-1}$ while the rest were around $760 \mathrm{~cm}^{-1}$. Apparently the Si:U ratio influenced the $\nu_{1}$ values. The $\mathrm{Si}: \mathrm{U}$ ratios of the studied uranyl silicates were mostly $1: 1$, with the exception of 1:2 for soddyite and 5:2 for haiweeite. The larger $\nu_{1}$ value of soddyite may be explained by its lower $\mathrm{Si}$ U ratio, leading to weaker equatorial U-silicate bonding, and hence, stronger bonding with the apical oxygens. The minor differences in $\nu_{1}$ between the 1:1 uranyl silicates probably resulted from other factors such as molecular symmetry, degree of hydration, and mineral crystallinity. These factors may also have influenced the band origins (i.e., the $0-0$ transition energy), the relative intensities of the vibronic bands, and fluorescence lifetimes of the different compounds.

It was noticed that a short wavelength band $(\sim 482 \mathrm{~nm})$ from synthetic boltwoodite appeared at room temperature but disap-
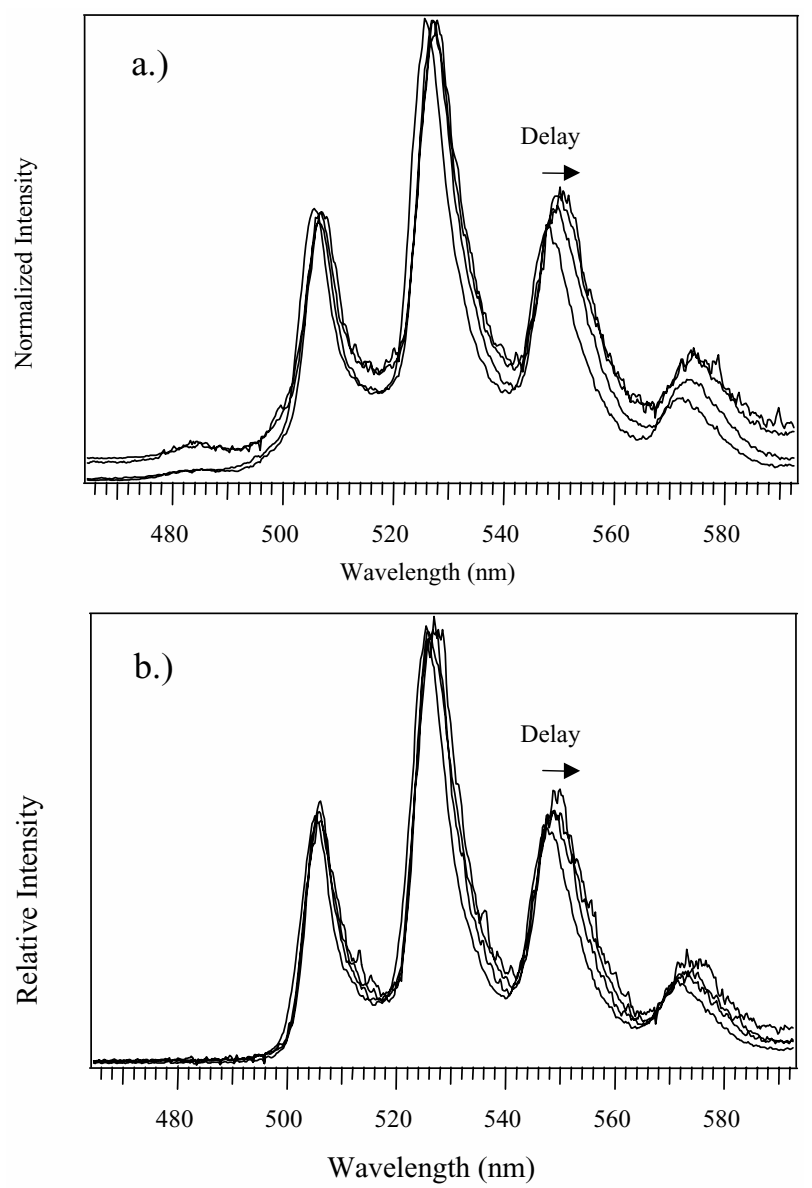

Fig. 9. Time-resolved fluorescence emission spectra of Hanford sediments $61 \mathrm{AB}$ (a) and $67 \mathrm{AB}$ (b) at $5.5 \mathrm{~K}$. $\lambda_{\text {ex }}=415 \mathrm{~nm}$. The time delays for the four spectral traces in the direction of the arrow are 1, 201, 401 and $801 \mu$ s, respectively. 
Table 4. Fluorescence spectral characteristics of Hanford sediment samples $\lambda_{\mathrm{ex}}=415 \mathrm{~nm}$.

\begin{tabular}{lccc}
\hline Sample & Spectral maxima $(\mathrm{nm})$ & $\begin{array}{c}\nu_{1}(\mathrm{f}) \\
\left(\mathrm{cm}^{-1}\right)\end{array}$ & $\begin{array}{c}\tau \text { at LHeT. } \\
(\mu \mathrm{s})\end{array}$ \\
\hline $53 \mathrm{~A}$ & $506.4,526.7,549.5,574.0$ & 782 & 291,85 \\
$61 \mathrm{~A}$ & $507.6,528.3,550.8,574.5$ & 761 & 467,137 \\
$61 \mathrm{AB}$ & $506.4,527.0,549.2,573.2$ & 765 & 447,127 \\
$67 \mathrm{AB}$ & $506.8,527.1,549.7,573.7$ & 771 & 452,165 \\
\hline
\end{tabular}

peared at liquid helium temperature. This band may originate from radiative transition from the second vibrational level $(\mathrm{v}=$ 1) of the excited state to the ground state. The population of this excited vibrational level is negligible at lowered temperatures, causing the disappearance of the band (Becquerel et al., 1909, 1910).

Despite the fact that uranyl silicates are relatively common secondary products at uranium deposits (Finch and Ewing, 1991; Pearcy et al., 1994), fluorescence measurements of these phases have been relatively scarce (deNeufville et al., 1981; Geipel et al., 2000). deNeufville et al. (1981) demonstrated that the weak fluorescence emissions from uranophane and $\beta$-uranophane at RT were increased by sample cooling to $77 \mathrm{~K}$. The RT fluorescence spectra of synthetic boltwoodite and soddyite reported by Vochten et al. (1995, 1997b) were similar to our observations. However, this work is the first systematic characterization of uranyl silicates by cryogenic fluorescence spectroscopy.

\subsection{Uranyl Silicates in Hanford Vadose Zone Sediments}

The well-resolved vibronic peaks in the fluorescence spectra of the four sediment samples (Fig. 8) indicated that the major fluorescent species was a crystalline uranyl phase. Time-resolved fluorescence spectra of all four samples (Fig. 9) showed only a small shift at delay times from $1 \mu$ s to $801 \mu$ s implying the presence of one dominant fluorescence U(VI) species. Fluorescence spectra obtained from the sediments after dissolution in $\mathrm{Na}$ - and $\mathrm{Ca}-\mathrm{HCO}_{3}$ electrolytes showed a decrease in spectral intensity but little change in peak position (Figs. 10 and 11). During this period 12.8 to $67.9 \%$ of the U(VI) phases were dissolved. The results implied partial dissolution of a single phase whose composition/structure was unchanged by electrolyte contact.

Fluorescence band spacings, of both the original and electrolyte-contacted sediments, varied from $761 \mathrm{~cm}^{-1}$ to 782 $\mathrm{cm}^{-1}$ (Table 4), which were consistent with those of uranyl silicates (Table 3). In contrast, band spacings for the uranyl ion are reported at $872 \mathrm{~cm}^{-1}$ (Morris et al., 1994) and at $\sim 825$ $\mathrm{cm}^{-1}$ for uranyl phosphates and carbonates (Geipel et al., 2000; Wang et al., 2003). The formation of uranyl phosphate, carbonate, silicates, and oxyhydroxides are all plausible in the Hanford sediments given the U-waste composition, the igneous character of the subsurface sediments, and the calcareous nature of vadose zone porewater. In addition, the presence of U(VI)-oxyhydroxides was not supported by our spectroscopic measurements as the spectra of these phases are usually broad and red-shifted (Perry and Brittain, 1984; Wang et al., 2003). Therefore, the relatively small $\nu_{1}$ values and the well resolved and intense peaks observed here from the sediments points to the presence of uranyl silicates.

The fluorescence spectra of the four sediments did not exactly match any of the reference uranyl silicates. The small $\nu_{1}$ values indicated that the sediment $\mathrm{U}(\mathrm{VI})$ silicate had a $\mathrm{Si}: \mathrm{U}$ ratio of 1:1 or higher. A comparison of the spectral profile of the sediment with those of the mineral specimens suggested that, within the error limit of the fluorescence measurement, the uranium species in the sediment were most similar to the uranophane group of uranyl silicates, namely, uranophane, boltwoodite, and cuprosklodowskite, or soddyite, for which, spectral similarity exists among them (Fig. 4). Using a procedure commonly adopted by X-ray spectroscopy (Behrens, 1992), the fluorescence spectra of both the sediments and the reference minerals were normalized, and the spectra of the sediments were fit with one, two and up to four combinations of the reference mineral spectra. The fitting results indicated that the best possible fit occurred with the inclusion of $53 \%$ boltwoodite, $42 \%$ uranophane, and $4 \%$ soddyite. The spectrum of the cuprosklodowskite, which was also similar to that of the sediment, was not included in this analysis because $\mathrm{Cu}$ was at low concentration in the sediment. These computed results were consistent with the $\nu_{1}$ values, as well as that of EXAFS spectral analysis (Catalano et al., 2003) and election microprobe analyses of the crystallites. The EMP analyses were most
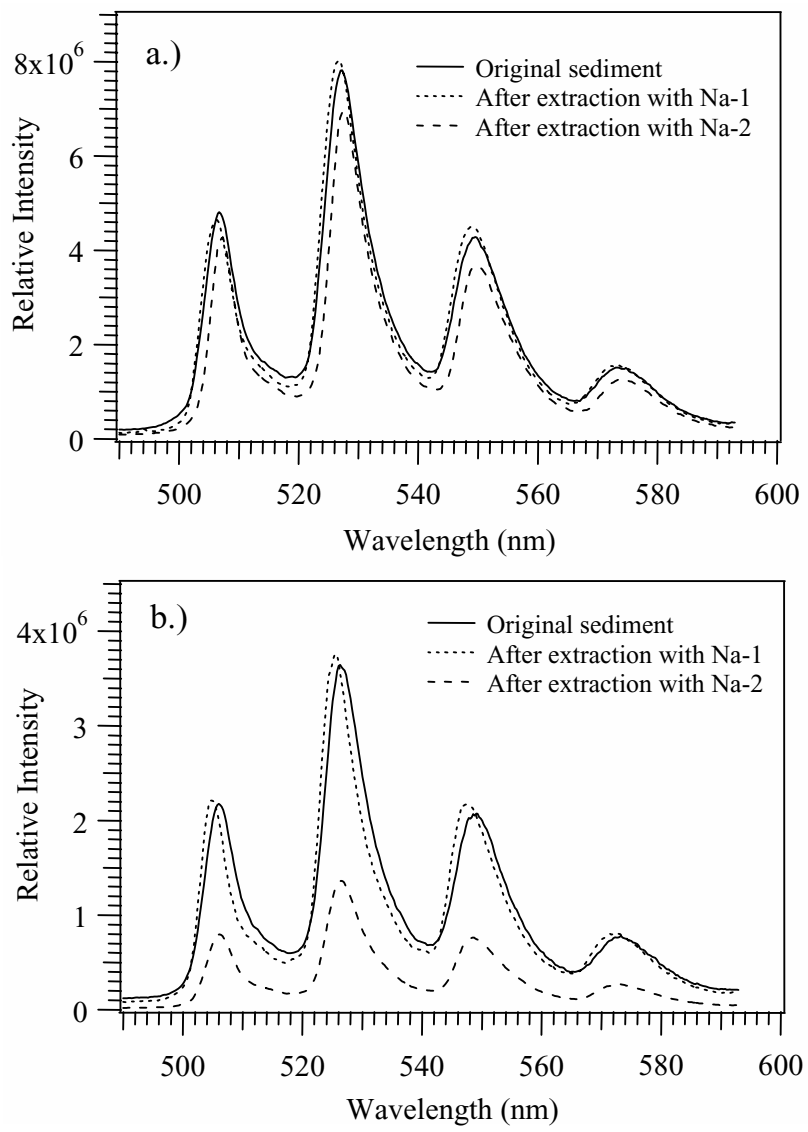

Fig. 10. Fluorescence emission spectra of Hanford sediments $61 \mathrm{AB}$ (a) and $67 \mathrm{AB}$ (b) before and after leaching with electrolyte solutions $\mathrm{Na}-1$ and $\mathrm{Na}-2$ at $5.2 \mathrm{~K}$. $\lambda_{\mathrm{ex}}=415 \mathrm{~nm}$. 

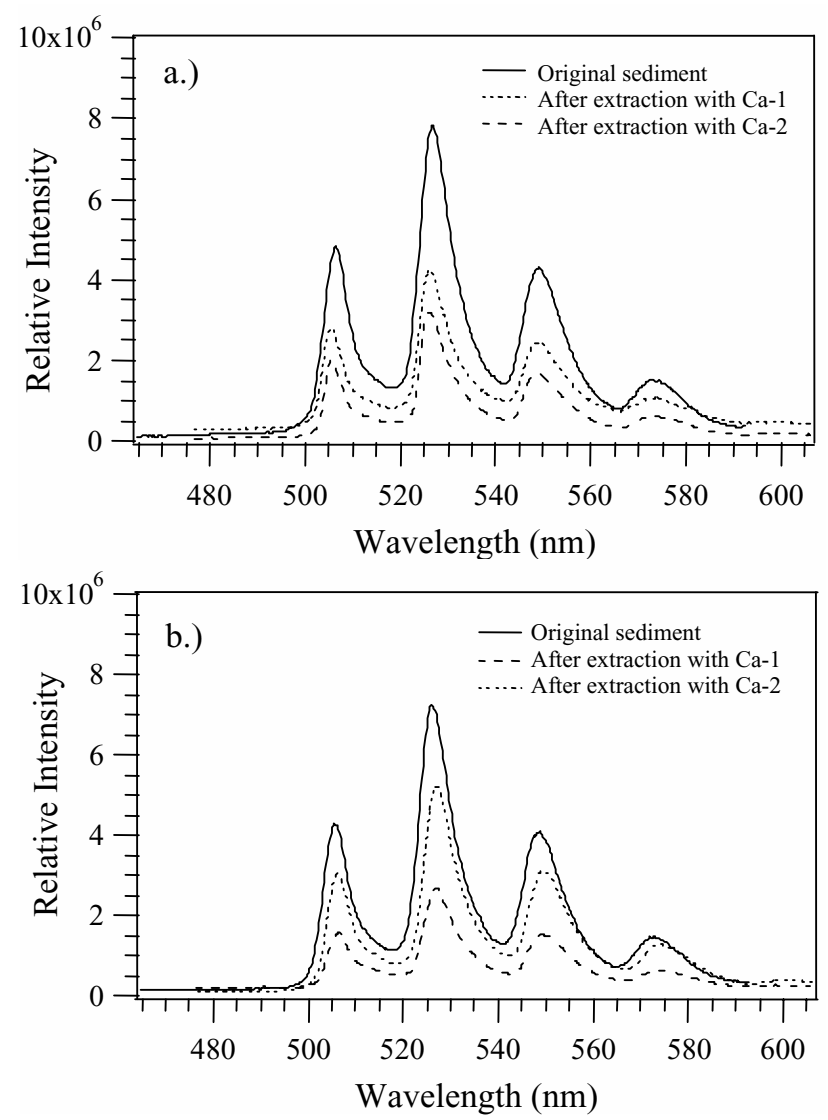

Fig. 11. Fluorescence emission spectra of Hanford sediments 61AB (a) and $67 \mathrm{AB}$ (b) before and after leaching with $\mathrm{CaCO}_{3(\mathrm{~s})}$ saturated electrolyte solutions, Ca-1 and Ca-2, at $5.2 \mathrm{~K} . \lambda_{\mathrm{ex}}=415 \mathrm{~nm}$.

consistent with soddyite or boltwoodite (McKinley et al., 2003).

The lack of an exact spectral match with any of the individual uranyl silicates may result from several reasons. One possibility is that the sediment phase contains a slightly different minor cation substitution pattern (e.g., $\mathrm{Ca}^{2+}, \mathrm{Mg}^{2+}, \mathrm{Na}^{+}, \mathrm{K}^{+}$) than the reference phases. The observed crystallites were found in internal grain fractures of both plagioclase and potassium feldspars and it is plausible that their cation concentrations may reflect the specific intragrain water composition of these materials. Similarly, $\mathrm{Al}(\mathrm{III})$, which is detected in the crystallites by EMP analysis, may be a structural substituent that affects fluorescence. It is also well known the fluorescence spectra of U(VI) minerals are sensitive to variations in hydration, weathering and aging (Perry and Brittain, 1984; Morris et al., 1996; Leung et al., 1999), and all of the above factors are plausible explanations. Other samples of uranyl silicates are currently being sought to expand our spectral database.

The presence of U(VI) silicates in Hanford subsurface sediments contrasts with other recent reports of U(VI) speciation in contaminated sediment. X-ray and fluorescence spectroscopic studies of soil from the U.S. DOE Fernald site in Ohio, indicated the formation of three different types of precipitates: (1) an autunite-like uranium phosphate precipitates with characteristic sharp green fluorescence bands, (2) a schoepite-like oxyhydroxide secondary minerals with broad, green fluores- cence emission, and (3) an ill-defined uranyl organic phase with orange fluorescence (Morris et al., 1996). At the DOE Savannah River Site in South Carolina, USA, most of the sediment U(VI) associates with particulate organic material and poorly crystalline iron oxides. The organically-complexed U(VI) displayed red-shifted fluorescence spectra as compared to aqueous uranyl (Hunter and Bertsch, 1998). U(VI) was found as sodium-calcium uranyl tricarbonates and U(VI)-hydroxide or hydroxycarbonate precipitates in California evaporation pond sediment (Duff et al., 2000). Aqueous calcium uranyl tricarbonate species were identified in calcium-rich seepage waters of a mine tailing pile in southeast Germany (Bernhard et al., 1996).

Curious were the differences between U(VI) speciation in Hanford (uranyl silicate) and Fernald sediments (autunite/ schoepite) given their comparable U(VI) concentration $(\sim 500$ $\mathrm{ppm})$. The waste source term at both sites contained significant phosphate (Womack and Larkin, 1971; Morris et al., 1996; Jones et al., 2001; Lichtner and Felmy, 2003). The preferential formation of the uranophane-type uranyl precipitates in the Hanford vadose zone may have resulted from (1) the abundance of unweathered silicates in the sediment, such as quartz and feldspar; (2) a waste $\mathrm{pH}(9-10)$ and temperature (60 to $80^{\circ} \mathrm{C}$ ) that encouraged $\mathrm{Si}$ dissolution and high solubility; (3)
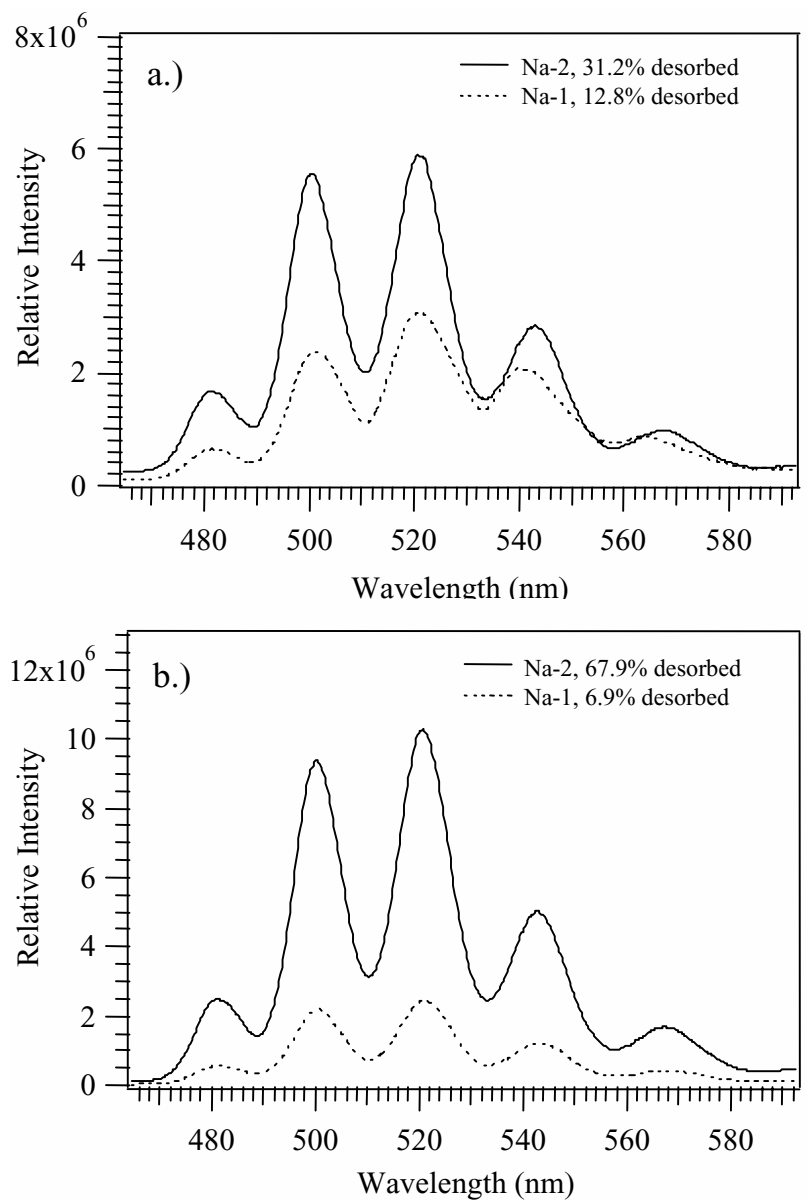

Fig. 12. Fluorescence emission spectra of dissolved uranyl in the electrolyte solutions Na-1 and Na-2 at $5.2 \mathrm{~K}$ from Hanford sediment $61 \mathrm{AB}$ (a) and $67 \mathrm{AB}(\mathrm{b}) . \lambda_{\mathrm{ex}}=415 \mathrm{~nm}$. 
significant ion-exchangeable $\mathrm{Ca}^{2+}$ that could react with $\mathrm{PO}_{4}^{3-}$ and precipitate; and (4) low volumetric water content that maintained fluid saturation of intragrain fractures. Supporting such explanation, boltwoodite is commonly found associated with quartz in the presence of uranium (Vochten et al., 1997b). Uranophane-type U(VI)-silicate minerals are important paragentic products found in oxidizing, water-unsaturated uranium ores (Finch and Ewing, 1991; Pearcy et al., 1994).

The formation of crystalline uranyl silicates in the Hanford vadose zone has significant implications to the future mobility of in-ground U(VI). These U(VI) silicates reside primarily in intra grain fractures, and they dissolve slowly because of kinetic and mass-transfer limitations (Liu et al., 2004). It has long been believed that vadose zone U(VI) at Hanford would be leachable to groundwater because of the limited potential of the calcareous, unweathered sediment to adsorb and precipitate $\mathrm{U}(\mathrm{VI})$ as a surface complex. Spectroscopic identification of the precipitates as uranyl silicates, along with the results of Liu et al. (2004), imply that the vadose zone U(VI) in this location will exhibit limited mobility to groundwater because of low uranyl silicate solubility and slow dissolution kinetics and diffusion rates from intragrain domains. It is further evident that the total concentration of U(VI) that may be released from these sediments will be strongly dependent on water content and phase composition because of the solubility control.

The sediment samples studied here $(53,61,67)$ represent a limited depth range $\left(118-141^{\prime}\right)$ from a single borehole. Consequently, the applicability of these findings to other locations at Hanford is not yet known. There are at least six other single shell waste tanks that released high U(VI) metal wastes to the vadose zone and the speciation of U(VI) beneath them is unstudied. Moreover, there are many other locations of U(VI) contamination at Hanford resulting from waste sources with different composition, temperature and release/dynamics. Hanford is only now beginning to speciate the U(VI) in these varied plumes. It is expected that other forms of precipitated U(VI) will be found as a result of differences in sediment and waste chemistry, and the nature of the reactive transport event.

\section{CONCLUSIONS}

Cryogenic uranyl fluorescence measurement at liquid helium temperature significantly enhanced both intensity of the fluorescence signal and spectral resolution of uranyl silicate minerals and U(VI)-contaminated Hanford vadose zone sediments. The cryogenic method offers improved possibilities for identifying uranyl species in complex environmental samples for which weak, broad, and featureless fluorescence spectra are usually observed at room temperature.

For the uranium silicate minerals, the symmetric vibration frequency, measured as the average of the peak spacing of the vibronic bands, ranged between $705 \mathrm{~cm}^{-1}$ and $823 \mathrm{~cm}^{-1}$, was much smaller than values reported for carbonates, phosphates and oxyhydroxides. A stronger interaction between silicate and the U(VI) in the equatorial plane was suggested.

The fluorescence emission spectrum of all four U(VI)-contaminated sediments (142 to $415 \mu \mathrm{g} / \mathrm{g}$ of total uranium) was quite similar, indicating the presence of a common U(VI) phase(s). Both the time resolved measurements and dissolution measurements showed little shift with delay indicating that most of the U(VI) was associated with a single type of U(VI) precipitate. The lack of change in the emission spectrum with the leaching of up to $60 \%$ of the precipitated U(VI) pool further indicated that only one dominant U(VI) phase was present. Spectral comparisons suggested that the U(VI)-silicate was a member of the uranophane group. While an exact match was not found between reference minerals and sediment, the unknown spectra was best simulated by assumed mixture of $57 \%$ of boltwoodite, $43 \%$ uranophane and $4 \%$ soddyite.

Acknowledgments - The authors are indebted to Dr. George Harlow at American Museum of Natural History (NY) and Dr. Jeff Post at the Smithsonian Institution for kindly providing the natural uranium mineral samples, Professor Sue Clark and Ms. Carrie Gillespie at WSU for synthesis of the boltwoodite, and Professor Peter Burns at the University of Notre Dame for providing the natural weeksite specimen. This project was supported by the DOE Hanford program, a project within Fluor Hanford's Groundwater Protection Program, and by the Environmental Management Sciences Program (EMSP) managed by the U.S. DOE Office of Biologic and Environmental Research (OBER). The fluorescence measurements were performed at the W.R. Wiley Environmental Molecular Sciences Laboratory, a national scientific user facility managed by the Department of Energy's Office of Biologic and Environmental Research and located at PNNL. Pacific Northwest National Laboratory is operated for the Department of Energy by Battelle Memorial Institute.

Associate editor: J. Rustad

\section{REFERENCES}

Azenha M. E. D. G., Burrows H., Formosinho S., and De Graca Miguel M. (1989) Photophysics of the excited uranyl ion in aqueous solutions. Part 6-Quenching effects of aliphatic alcohols. J. Chem. Soc. Faraday Trans. I 85, 2625-2634.

Baird C. P. and Kemp T. J. (1997) Luminescence, spectroscopy, lifetimes and quenching mechanisms of excited states of uranyl and other actinide ions. Prog. Reaction Kinetics 22, 87-139.

Balzani V., Bolleta F., Gandolfi M. T., and Maestri M. (1978) Bimolecular electron transfer reactions of the excited states of transition metal complexes. Topics Curr. Chem. 75, 1-64.

Bargar J. R., Reitmeyer R., and Davis J. A. (1999) Spectroscopic confirmation of uranium(VI) - Carbonato adsorption complexes on hematite. Environ. Sci. Technol. 33, 2481-2484.

Bargar J. R., Reitmeyer R., Lenhart J. J., and Davis J. A. (2000) Characterization of $\mathrm{U}(\mathrm{VI})$-carbonato ternary complexes on hematite: EXAFS and electrophoretic mobility measurements. Geochim. et Cosmochim. Acta 64, 2737-2749.

Barnett M. O., Jardine P. M., and Brooks S. C. (2002) U(VI) adsorption to heterogeneous subsurface media: Application of a surface complexation model. Environ. Sci. Technol. 36, 937-942.

Becquerel H., Becquerel J., and Onnes H. K. (1909) On phosphorescence at very low temperatures. Verslag Akad. Wetenschap. Amsterdam 17, 1045-1057.

Becquerel H., Becquerel J., and Onnes H. K. (1910) Phosphorescence des sels D'uranyle aux tres basses temperatures. Ann. Chim. Phys. 8 20, 14519.

Beechem J. M., Gratton E., and Mantulin W. W. (1991) Globals Unlimited. UIUC Publication.

Behrens P. (1992) X-ray absorption spectroscopy in chemistry II. X-ray absorption near edge structure. Trends Anal. Chem. 11, 237-244.

Bernhard G., Geipel G., Brendler V., and Nitsche H. (1996) Speciation of uranium in seepage waters of a mine trailing pile studied by time-resolved laser-induced fluorescence spectroscopy (TRLFS). Radiochim. Acta

Borovec Z. (1981) The adsorption of uranyl species by fine clay. Chem. Geol. 32, 45-58.

Bostick B. C., Fendorf S., Barnett M. O., Jardine P. M., and Brooks S. C. (2002) Uranyl surface complexes formed on subsurface media from DOE facilities. Soil Sci. Soc. Am. J. 66, 99-108. 
Brittain H. G. and Perry D. L. (1980) Luminescence spectra of the uranyl ion in two geometrically similar coordination environments: Uranyl nitrate hexahydrate and $\mathrm{Di}-\mu$-aquo-bis[dioxobis(nitrato)uranium(VI)]Diimidazole. J. Phys. Chem. 84, 2630-2634.

Burns P. C. (2001) A new uranyl silicate sheet in the structure of haiweeite and comparison to other uranyl silicates. Can. Miner. 39, 1153-1160.

Burrows H. D., Formosinho S., De Graca Miguel M., and Coelho F. P. (1975) Quenching of the luminescence state of the uyanyl ion $\left(\mathrm{UO}_{2}{ }^{2+}\right)$ by metal ions. J. Chem. Soc. Faraday Trans. 72, 163-171.

Burrows H., Cardoso A., Formosinho S., and Miguel M. (1985) Photophysics of the excited uranyl ion in aqueous solutions. J. Chem. Soc. 81, 49-60.

Burrows H. D., Formosinho S. J., and Pedrosa M. A. (1986) Anemission spectral study of uranyl ion binding to $\alpha$-alumina. J. Mol. Struct. 143, 223-226.

Burrows H. and Miguel M. (2001) Applications and limitations of uranyl ion as a photophysical probe. Adv. Colloid Interface Sci. 89, 485-496.

Catalano J. G., Heald S. M., Zachara J. M., and Brown G. E., Jr. (2003) Spectroscopic and diffraction study of uranium speciation in contaminated vadose zone sediments from the Hanford site, Washington. Environ. Sci. Technol. 38, 2822-2828.

Cejka J. (1999) Infrared spectroscopy and thermal analysis of the uranyl minerals. In Uranium: Mineralogy, Geochemistry and the Environment" (eds. P. C. Burns and R. Finch), pp. 521-622. Reviews in Mineralogy 38. Mineralogical Society of America, Washington, D.C.

Cejka J. and Urbanec Z. (1990) Secondary uranium minerals: The mineralogy, geochemistry and crystal chemistry of the secondary uranium (VI) minerals. Transactions of the Czechoslovak Academy of Sciences, Math Natural History Series 100, Academia, Prague.

Clark D. L., Conradson S. D., Donohoe R. J., Keogh D. W., Morris D. E., Palmer P. D., Rogers R. D., and Tait C. D. (1999) Chemical speciation of the uranyl ion under highly alkaline conditions, synthesis, structures and oxo ligand exchange dynamics. Inorg. Chem. 38, 1456-1466.

deNeufville J. P., Kasdan A., and Chimenti R. J. L. (1981) Selective detection of uranium by laser-induced fluorescence: A potential remote-sensing technique. 1: Optical characteristics of uranyl geologic targets. Appl. Opt. 20, 1279-1296.

Denning R. G. (1992) Electronic structure and bonding in actinyl Ions. Struct. Bond. 79, 215-276.

Dent A. J., Ramasay J. D. F., and Swanton S. W. (1992) An EXAFS study of uranyl in solution and sorbed onto silica and montmorillonite clay colloids. J. Colloids and interface Sci. 150, 45-60.

Duff M. C., Amrhein C., Bertsch P. M., and Hunter D. B. (1997) The chemistry of uranium in evaporation pond sediment in the San Joaquin Valley, California, USA, using X-ray fluorescence and XANES techniques. Geochim. Cosmochim. Acta 61, 73-81.

Duff M. C., Morris D. E., Hunter D. B., and Bertsch P. M. (2000) Spectroscopic characterization of uranium in evaporation basin sediments. Geochim. Cosmochim. Acta 64, 1535-1550.

Finch R. and Murakami T. (1999) Systematics and paragenesis of uranium minerals. In Uranium: Mineralogy, Geochemistry and the Environment" (eds. P. C. Burns and R. Finch), pp. 91-179. Reviews in Mineralogy 38. Mineralogical Society of America, Washington, D.C.

Finch R. J. and Ewing R. C. (1991) Alteration of natural $\mathrm{UO}_{2}$ under oxidizing conditions from Shinkolobwe, Katanga, Zaire: A natural analogue for the corrosion of spent fuel. Radiochim. Acta 52/53, 395-401.

Flint C. D. and Tanner P. A. (1978) Luminescence spectra of $\mathrm{Cs}_{2} \mathrm{UO}_{2} \mathrm{Cl}_{4}$. J. Chem. Soc. Faraday Trans. II 74, 2210-2217.

Geipel G., Bernhard G., Rutsch M., Brendler V., and Nitsche H. (2000) Spectroscopic properties of uranium(VI) minerals studied by timeresolved laser-induced fluorescence spectroscopy (TRLFS). Radiochim. Acta 88, 757-762.

Hudson E. A., Terminello L. J., Viani B. E., Denecke M. A., Reich T., Allen P. G., Bucher J. J., Shuh D. K., and Edelstein N. M. (1999) The structure of $\mathrm{U}^{6+}$ sorption complexes on vermiculite and hydrobiotite. Clays Clay Miner. 47, 439-457.
Hunter D. B. and Bertsch P. M. (1998) In situ examination of uranium contaminated soil particles by micro-X-ray absorption and microfluorescence spectroscopies. J. Radioanal. Nucl. Chem. 234, 237242

Jankowiak R. and Small G. J. (1989) Fluorescence line-narrowing spectroscopy in the study of chemical carcinogenesis. Anal. Chem. 61 (18), 1023A-1032A.

Jones T. E., Simpson B. C., Wood M. I., and Corbin R. A. (2001) Preliminary estimates for single-shell tank leaks in B, BX and BY tank farms, RPP-7389, CH2MHILL. Richland, WA, Hanford Group.

Lakowicz J. and Weber G. (1973) Quenching of fluorescence by oxygen: A probe for structural fluctuations in macromolecules. Biochemistry 12, 4161-4170.

Leung A. F., Hayashibara L., and Spadaro J. (1999) Fluorescence properties of uranyl nitrates. J. Phys. Chem. Solids 60, 299-304.

Lichtner P. C. and Felmy A. R. (2003) Estimation of Hanford SX tank waste compositions from historically derived inventories. Comput. Geosci. 29, 371-383.

Liu C., Zachara J. M., Qafoku O., McKinley J. P., Heald S. M., and Wang Z. (2003) Dissolution of uranyl microprecipitates from subsurface sediments at Hanford Site, USA. Geochim. Cosmochim. Acta 68, 4519-4537.

Marcantonatos M. D. (1979a) Chemical quenching by water of the photoexcited uranyl ion in aqueous acidic solution. J. Chem. Soc. Faraday Trans. 75, 2273-2284.

Marcantonatos M. D. (1979b) Mechanism of interactions between aquo-metallic complexes and the photoexcited aquo-uranyl(VI) ion. J. Chem. Soc. Faraday Trans. 75, 2252-2272.

McKinley J. P., Heald S. M., Zachara J. M., and Resch C. T. (2003) The identification of uranium-bearing phases by X-ray microprobe, electron microprobe, and scanning electron microscopy. In Digest of Science and Technology Program Evaluation. Hanford Vadose Zone Report (RPP-10098), pp. 89-107. Richland, WA, Pacific Northwest National Laboratory.

McKinley J. P., Zachara J. M., Smith S. C., and Turner G. D. (1995) The influence of uranyl hydrolysis and multiple site-binding reactions on adsorption of $\mathrm{U}(\mathrm{VI})$ to montmorillonite. Clays Clay Miner. 43, 586-598

Meinrath G. (1997) Uranium (VI) speciation by spectroscopy. J. Radioanal. Nucl. Chem. 224, 119-126.

Moriyasu M., Yokoyama Y., and Ikeda S. (1977) Anion coordination to uranyl ion and the luminescence lifetime of the uranyl complex. J. Inorg. Nucl. Chem. 39, 2199-2203.

Morris D. E., Chisholm-Brause C. J., Barr M., Conradson S. D., and Eller P. G. (1994) Optical spectroscopic studies of the sorption of $\mathrm{UO}_{2}{ }^{2+}$ species on a reference smectite. Geochim. Cosmochim. Acta 58, 3613-3623.

Morris D. E., Allen P. G., Berg J. M., Chisholm-Brause C. J., Conradson S. D., Donohoe R. J., Hess N. J., Musgrave J. A., and Tait C. D. (1996) Speciation of uranium in fernald soils by molecular spectroscopic methods: Characterization of untreated soils. Environ. Sci. Technol. 30, 2322-2331.

Pabalan R. T. and Turner D. T. (1996) Uranium (6+) sorption on montmorillonite: Experimental and surface complexation modeling study. Aquatic Geochem. 2, 203-226.

Pearcy E. C., Prikryl J. D., Murphy W. M., and Leslie B. W. (1994) Alterration of uraninite from the Nopal I deposit, Pena Blanca District, Chihuahua, Mexico, compared to degradation of spent nuclear fuel in the proposed U.S. high-level nuclear waste repository at Yucca Mountain, Nevada. Appl. Geochem. 9, 713-732.

Pearson R. G. Hard and soft acids and bases. (1963) J. Am. Chem. Soc. $\mathbf{8 5}, 3533$.

Perry D. L. and Brittain H. G. (1984) Photophysical studies of uranyl complexes. 4. X-ray photoelectron and luminescence studies of hydrolyzed uranyl salts. Inorg. Chem. 23, 1232-1237.

Rabinowitch E. and Belford R. L. (1964) Spectroscopy and photochemistry of uranyl compounds. McMillan, N. Y.

Riley R. G. and Zachara J. M. (1992) Chem. contaminants on DOE lands and selection of contaminant mixtures for subsurface science research. DOE/ER-0547T. U.S. Department of Energy, Office of Energy Research. 
Samojlov B. N. (1948) Absorption and luminescence spectra of uranyl salts at the temperature of liquid helium. Zhur. Eksptl. Teoret. Fiz. 18, 1030-1040.

Serne R. J., Bjornstad B. N., Gee G. W., Schaef H. T., Lanigan D. C., Lindenmeirer C. W., Orr R. D., LeGore V. L., Clayton R. E., Lindberg M. J., Kutnyakov I. V., Baum S. R., Geiszler K. N., Valenta M. M., Vickerman T. S., and Royack L. J. (2002) Characterization of Vadose zone sediment: Borehole 299-E33-46 near tank B-110 in the B-BX-BY waste management area. Pacific Northwest National Laboratory, Richland, WA.

Sylwester E. R., Hudson E. A., and Allen P. G. (2000) The structure of uranium (VI) sorption complexes on silica, alumina and montmorillonite. Geochim. Cosmochim. Acta 64, 2431-2438.

Thompson H. A., Parks G. A., and Brown J. G. E. (1998) Structure and composition of uranium(VI) sorption complexes at the kaolinitewater interface. In Adsorption of Metals by Geomedia: Variables, Mechanisms and Model Applications (ed. E. A. Jenne), pp. 349370. Academic Press.

Turner G. D., Zachara J. M., McKinley J. P., and Smith S. C. (1996) Surface-charge properties and $\mathrm{UO}_{2}{ }^{2+}$ adsorption of a subsurface smectite. Geochim. Cosmochim. Acta 60 (18), 3399-3414.

Vochten R., Blaton N., and Peeters O. (1997a) Synthesis of sodium weeksite and its transformation into weeksite. N. Jb. Miner. Mh. 12, $569-576$.

Vochten R., Blaton N., Peeters O., van Springel K., and van Haverbeke L. (1997b) A new method of synthesis of boltwoodite and of formation of sodium boltwoodite, uranophane, sklodowskite and kasolite from boltwoodite. Can. Mineral. 35, 735-741.

Vochten R., van Haverbeke L., van Springel K., and De Grave E. (1995) Soddyite: Synthesis under elevated temperature and pressure and the study of some physicochemical characteristics. $N$. Jb. Miner. Mh. 10, 470-480.

Volodko L. V., Komyak A. I., Sevchenko A. N., and Umreiko D. S. (1974) Spectral-luminescent study of crystals of uranyl compounds. J. Luminescence 8, 198-202.

Waite T. D., Davis J. A., Payne T. E., Waychunas G. A., and Xu N. (1994) Uranium (VI) adsorption to ferrihydrite: Application of a surface complexation model. Geochim. Cosmochim. Acta 58 (24), 5465-5478.

Wang Z., Zachara J. M., Gassman P. L., Joly A. G., Liu C. X., and Catalano J. (2003a) Fluorescence spectroscopic studies of uraniumbearing vadoze zone sediments. In Digest of Science and Technology Program Evaluation, Hanford Vadoze Zone Report (RPP10098). pp. 130-161. Richland, WA, Pacific Northwest National Laboratory.

Wang Z., Zachara J. M., Yantasee W., Gassman P. L., Liu C. X., and Joly A. G. (2004) Cryogenic Laser Induced Fluorescence Characterization of U (VI) in Hanford Vadose Zone Porewaters. Environ. Sci. Technol. 38, 5591-5597.

Womack J. C. and Larkin D. J. (1971) Investigation and evaluation of 102-BX tank leak, ARH-2035. Richland, WA, Atlantic Richfield Hanford. 